\title{
Tailoring interventions: identifying predictors of poor asthma control
}

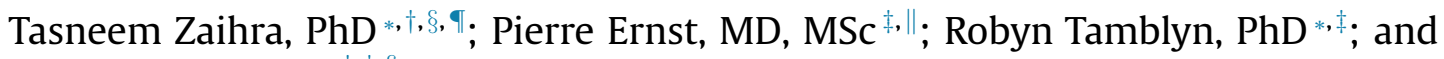 \\ Sara Ahmed, PhD $*+,+, \delta$ \\ ${ }^{*}$ Clinical Epidemiology, McGill University Health Center, Montreal, Quebec, Canada \\ ${ }^{\dagger}$ School of Physical and Occupational Therapy, Faculty of Medicine, McGill University, Montreal, Quebec, Canada \\ ${ }^{\ddagger}$ Department of Epidemiology and Biostatistics, Faculty of Medicine, McGill University, Montreal, Quebec, Canada \\ ${ }^{\S}$ Centre de recherche interdisciplinaire en réadaptation (CRIR), Montreal, Quebec, Canada \\ "Centre for Clinical Epidemiology, Lady Davis Institute for Medical Research, Jewish General Hospital, McGill University, Montreal, Quebec, Canada \\ ${ }^{\top}$ Department of Mathematics, Brockport College, State University of New York, Brockport, New York
}

\section{A R T I C L E I N F O}

\section{Article history:}

Received for publication November 4, 2014

Received in revised form March 16, 2015.

Accepted for publication March 17, 2015.

\section{A B S T R A C T}

Background: Determining the factors that will predict long-term asthma control is essential for improving health outcomes and decreasing the burden on the health care system. Patient-reported outcomes (PROs) on health behaviors can provide valuable information about future asthma control but have rarely been considered in previous analyses.

Objective: To develop statistical models for evaluating the predictors of long-term asthma control using PROs such as scores of the Asthma Control Test and the Asthma Self-Efficacy Scale.

Methods: Of 1,437 individuals contacted, 566 (39\%) at baseline and 486 (34\%) at follow-up completed the questionnaires, including 4 PROs (Asthma Control Test, Asthma Self-Efficacy Scale, Mini-Asthma Quality of Life Questionnaire, and Beliefs about Medication Questionnaire). Long-term asthma control was evaluated by assessing overuse of rescue medication and emergency department visits. A multivariate logistic generalized estimating equation model was fitted to evaluate the possible effect of the studied factors on asthma control. Results: The complete case generalized estimating equation analysis included 286 participants who had complete PROs at the 2 evaluation times. After adjusting for socioeconomic status and smoking status, the Mini-Asthma Quality of Life Questionnaire was a significant predictor of asthma exacerbation. For each 1point increase on the Mini-Asthma Quality of Life Questionnaire, there was a 0.25 decrease in the odds of a patient's asthma getting out of control.

Conclusion: These findings suggest opportunities to decrease the burden on health care by tailoring interventions that combine PROs with other clinical and sociodemographic variables.

(c) 2015 American College of Allergy, Asthma \& Immunology. Published by Elsevier Inc. All rights reserved.

\section{Introduction}

Despite advances in the development of medications and guidelines for diagnosis and management, asthma remains an important health problem. ${ }^{1,2}$ The primary goal of asthma treatment is for patients to maintain disease control, in part by the absence of asthma exacerbations. ${ }^{3}$ The large proportion of individuals with poor control contributes to increased usage of health care resources and high health care costs. ${ }^{4-8}$ Existing evidence suggests that considerable decreases in morbidity could be achieved by the prevention,

Reprints: Sara Ahmed, PhD, Associate Professor, Faculty of Medicine, McGill University, 3654 Prom Sir-William-Osler, Montreal, QC, Canada H3G 1Y5; E-mail: sara. ahmed@mcgill.ca.

Disclosure: Authors have nothing to disclose.

Funding: A grant from GlaxoSmithKline supported this work. Dr Ahmed is supported through a career award from the Fonds de la Recherche en Santé du Quebec. Dr Zaihra was supported through a postdoctoral fellowship in respiratory medicine from the Richard and Edith Strauss Foundation. early detection, and timely treatment of asthma exacerbations that result from poor disease control and poor lung function. ${ }^{1,9}$

Providing appropriate treatment and improving health outcomes for asthma require a mechanism for identifying patients at risk of developing asthma exacerbations. This means determining the factors associated with poor asthma control. Delineating such predictors can help identify patients in need of further intervention and could help the health care team tailor patient-centered interventions in a way that will maximize the derived benefits for individual patients. Therefore, for this study, the authors defined an algorithm based on the recommendation of Kawasumi et al, ${ }^{10}$ which identifies patients who experience serious adverse asthma exacerbations and then receive medical services in an emergency department (ED) or overuse controller medications or fast-acting $\beta$-agonists (FABAs) or fill at least 1 prescription for oral steroids.

Most studies that have examined predictors of asthma exacerbations have focused on clinical and laboratory measurements. Studies also have identified patient characteristics, such as 
socioeconomic status (SES), age, sex, body mass index, and smoking status, as significant predictors of poor asthma control. ${ }^{11-13}$ Similarly, patient-reported outcomes (PROs) and previous health care usage have been shown to predict asthma exacerbations 12 months later. ${ }^{10}$ Other key predictors of poor asthma control have included poor access to care and poor quality of care that have been related to characteristics of the primary care physician responsible for the patient's asthma management. ${ }^{13,14}$

Less attention has been devoted to evaluating the influence of patient health behaviors on asthma control, which are potentially modifiable patient characteristics. There is increasing recognition that greater attention to patient behaviors and their influence on future outcomes will likely play an important role in improving health outcomes for asthma. ${ }^{15-18}$ The influence of personality traits and beliefs about medicines on adherence to asthma treatment have been recognized as an important factor in predicting asthma exacerbations. ${ }^{19}$ The relation among self-management, self-efficacy and improved health behaviors and clinical outcomes also has been shown in other chronic conditions. ${ }^{20-24}$ These included improved ability to manage pain, less depression, increased frequency of exercise, using medicine as prescribed, managing stress, and following a recommended diet.

Integration of the clinical markers of asthma control with PROs has been identified as crucial for evaluating the risk of asthma exacerbations in patients, which in turn helps in planning patientspecific interventions. ${ }^{25,26}$ The purpose of this study was to evaluate and compare the independent predictive ability of PROs, including self-perceived asthma control, self-efficacy, and perception about quality of life and beliefs about medications, for the risk of asthma exacerbations. The authors hypothesized that all these would be significant predictors. A secondary objective was to evaluate the interaction between self-efficacy and self-perceived asthma control because the authors hypothesized that self-reported symptoms in those more confident in managing their asthma symptoms would have significantly fewer future asthma exacerbations.

\section{Methods}

\section{Study Participants and Procedure}

Participants for this study were identified through primary care physicians participating in the Medical Office of the 21st Century (MOXXI) study ${ }^{27}$ who were in full-time fee-for-service practices in a large metropolitan area. Primary care physicians were identified by professional association master lists and contacted by letter and telephone to determine their interest in participating in the MOXXI project. Patients of these physicians were identified from the Quebec provincial health database, La Régie de l'assurance maladie du Québec (RAMQ), by medical service claims and physician and beneficiary files. Individuals with probable asthma were identified through the MOXXI system using information on written and dispensed prescriptions and medical services claims diagnostic codes based on algorithms validated in prior research. ${ }^{28}$ Participants at least 18 years of age who consented to the MOXXI project and who had a confirmed diagnosis of asthma were called by a member of the research team and invited to participate in the study.

The institutional review board of McGill University (Montreal, Quebec, Canada) approved this study.

\section{Measurements}

\section{Patient-reported outcomes}

The following patient-reported questionnaires were completed over the phone at 2 time points a year apart, namely at baseline and at follow-up.

Asthma Self Efficacy Scale. The Asthma Self Efficacy Scale measures confidence in managing situations that precipitate asthma. The
ASES asks patients to rate their confidence in avoiding an asthma attack in different situations encompassing activities, interactions with others, and feelings or emotions. The ASES is based on basic self-efficacy theories that state that patients' perceptions of their own capabilities will affect their motivations, coping behaviors, and ability to maintain certain behaviors. ${ }^{29}$ Previous studies have supported the validity and reliability of the ASES. ${ }^{30,31}$

Asthma Control Test. The Asthma Control Test (ACT), a 5-point patient-administered survey for assessing asthma control, has emerged as a simple and quick tool for evaluating patient-reported asthma control. ${ }^{32,33}$ In addition to asking about asthma symptoms during the past 4 weeks, the ACT asks patients to rate their overall level of asthma control. The reliability, validity, and responsiveness of the ACT have been tested in a sample of patients new to the care of an asthma specialist. The ACT has been found to be internally consistent (Cronbach $\alpha=0.85)^{33}$ and to have moderate test and retest reliability (intra-cluster correlation $=0.77$ ).

Beliefs about Medicines Questionnaire. Patient's beliefs about their medicines were evaluated using the Beliefs about Medicines Questionnaire (BMQ). ${ }^{34,35}$ The BMQ is comprised of 25 -item Likert scales assessing patients' beliefs about the "necessity" of prescribed medication for controlling their illness and their "concerns" about the potential adverse consequences of taking it. The necessity concern differential score was calculated by subtracting the specific concerns scale from the specific necessity scale (range -20 to 20 ). ${ }^{19}$ A positive differential score indicates that the patient has stronger beliefs in the necessity of medications compared with concerns and vice versa in the case of a negative score. Emilsson et $\mathrm{al}^{19}$ found the 2 subscales of the BMQ to be internally consistent with the Cronbach $\alpha$ for the specific necessity and concern scales ( 0.87 and 0.78 , respectively).

Mini-Asthma Quality of Life Questionnaire. The Mini-Asthma Quality of Life Questionnaire (MAQLQ) is a shorter but more efficient version of the original Asthma Quality of Life Questionnaire (AQLQ). It was developed and fully validated by Juniper et al. ${ }^{35}$ The MAQLQ has 15 questions in the same domains as the original AQLQ (symptoms, activities, emotions, and environment). A score can be derived for each domain and for an overall composite score. Items are scored on a scale from 1 to 7 , with a higher score reflecting better status.

\section{Patient's sociodemographic characteristics}

Sex, age, and indicators of SES (eg, household income) were obtained from the RAMQ. Age was categorized into 3 groups (18-39, 40-59, and $\geq 60$ years old). Average household income obtained by each subject's residential postal code was used as an indicator of income data and the corresponding SES of the study participant. Furthermore, it was divided into 3 income groups: low (income $\leq \$ 31,753$ ), middle (income $\$ 31,753-\$ 80,000$ ) and high $(>\$ 80,000)$. Thus, subjects were allocated to 1 of 3 categories of SES based on the average household income of residents in their postal code area. ${ }^{36}$

\section{Comorbidity conditions}

Patients' smoking status during the past year also was evaluated by telephone interview. Subjects were considered smokers if they smoked at least 1 cigarette per day over a 1 -year period before recruitment. In accord with the study by Kawasumi et al, ${ }^{10} 2$ categories of medical conditions, as factors that can influence asthma presentation and management, namely "somatic complaints and neurotic disorder" and "cardiac-related conditions," were created.

\section{Asthma control}

The number of doses of FABAs dispensed was based on records of dispensed prescriptions in the prescription claims file of the 
RAMQ and private pharmacy prescription files (Table 1). Asthmarelated ED visits and hospitalizations were identified through the RAMQ medical service claims diagnostic code. Based on a previously validated algorithm, a patient's asthma is considered out of control if the sum of the quantity for all FABAs dispensed to the patient within the past 12 months exceeds 1,000 doses (1,000 doses is based on the most commonly prescribed FABA, salbutamol, at $100 \mu \mathrm{g}$ and 2 inhalations at a time or the equivalent for other fastacting bronchodilators in the past 12 months $)^{37}$ and/or they visited an ED for a respiratory-related problem in the past year. Baseline values for use of FABA ${ }^{38}$ and ED visits were evaluated over a 1-year period before recruitment. Follow-up values were calculated over a 1 -year period after recruitment. In summary, a patient's asthma was designated as out of control if the patient visited the ED for a respiratory problem during the 12-month follow-up period or overused FABAs.

\section{Data Analyses}

Descriptive statistics were used to evaluate the characteristics of patients in the study. Spearman and Pearson correlation coefficients were used to assess relations between the predictor variables based on PROs at the baseline and follow-up evaluations. Mean values and variability in the scores of the patient-reported predictive measurements also were examined. To determine whether a patient's self-efficacy in particular and other PROs, such as scores from the ACT, MAQLQ and BMQ, were independent predictors of a patient's asthma control while adjusting for potential confounders, such as age, sex, SES, and effect modifiers, such as comorbidities, the authors fitted a multivariate logistic GEE model. Patients were clustered within physicians with an exchangeable correlation structure and each patient was observed longitudinally between the baseline and follow-up times. The GEE model describes how the average response across patients (or "clusters") changes with the covariates. The focus is on the relation between the covariates and the probability of response, and the correlation (dependence) of response within a patient is treated as a nuisance parameter. Furthermore, patients were assumed nested within physicians. The unit of analysis was the patient, with the patient's asthma control status as the outcome of interest. The interaction effect between the ASES and ACT was added because the authors believed that the impact of self-perceived asthma control might be different among individuals reporting high vs low levels of selfefficacy. Also, to avoid a high correlation between the model coefficients of the PROs owing to multi-colinearity, the ACT, MAQLQ ASES, and BMQ scores were centered (with centering, only individual coefficients of the main effects that are centered change in the model; everything else remains same). The goodness-of-fit criterion used for the fitted GEE models was the model QIC value $^{39,40}$; smaller QICu values are indicators of better model fit. The PROs for some patients were unavailable at the follow-up evaluation and were handled as missing. Sensitivity analysis was performed to assess the pattern of missing data and to evaluate how missing data might affect modeling. The authors used 2 multiple imputation methods that assume missing completely at random (Markov Chain Monte Carlo method ${ }^{41}$ and monotone missing data pattern method) for sensitivity analysis. ${ }^{42,43}$ All statistical analyses were conducted using Procedure Proc MIANALYZE in SAS 9.3 (SAS Institute, Cary, North Carolina).

\section{Results}

Of the 1,437 individuals contacted, 442 (31\%) completed the questionnaires, including the 4 PROs (ACT, MAQLQ, ASES, BMQ), at the baseline and follow-up evaluation times. Of these 442, 286 participants had complete data on all 4 PROs at the 2 time points (Fig 1). The remaining 156 participants had at least 1 missing PRO
Table 1

Missing data pattern at follow-up evaluation

\begin{tabular}{lllllrr}
\hline Group & ACT & BMQ & ASES & AQLQ & Frequency & \multicolumn{1}{c}{$\%$} \\
\hline 1 & X & X & X & X & 286 & 64.71 \\
2 & X & X & X & - & 3 & 0.68 \\
3 & X & X & - & - & 1 & 0.23 \\
4 & X & - & - & - & 14 & 3.17 \\
5 & - & X & X & X & 29 & 6.56 \\
6 & - & - & - & - & 109 & 24.66 \\
\hline
\end{tabular}

Abbreviations: - , missing; ACT, Asthma Control Test; AQLQ Asthma Quality of Life Questionnaire; ASES, Asthma Self-Efficacy Scale; BMQ Beliefs about Medications Questionnaire; X, not missing.

datum at the follow-up evaluation. Table 1 presents the distribution of the missing data.

There were no statistically significant differences in sociodemographic information, overuse of FABA, and ED visits for a respiratory problem between those who responded to the telephone interview and the $61 \%$ who refused. The only 2 variables that were significantly different were sex and smoking status. Most subjects who responded were female (70\%), whereas most subjects who did not respond were male (69\%), and this difference in the proportion of male vs female participants was statistically significant $(P<.001)$. Also, $12 \%$ of respondents smoked regularly vs $1 \%$ of nonrespondents, and this difference in the percentage of smokers between the respondents and nonrespondents was statistically significant $(P<.001$; eTable 1$)$.

Tables 2 and 3 present the baseline and follow-up characteristics of the 286 subjects with complete PROs at the follow-up evaluation compared with the 156 patients with at least 1 PRO missing at follow-up. The mean, range, and SD of baseline scores of the PROs for the 286 patients vs the 156 patients with at least 1 PRO missing at follow-up were similar, except for the average ASES scores. The mean ASES score for the 286 patients at the baseline evaluation was 4.2 (range 1.1-5.0) compared with the remaining 156 patients whose mean ASES score was 4.0 (range 1.2-5.0). The difference in the mean ASES scores of the 286 patients vs the remaining 156 patients at the baseline evaluation was statistically significant $(P=$ .007). The remaining sociodemographic characteristics of the 2 groups were similar for most variables.

Table 4 presents the basic descriptive statistics for the scores obtained from the questionnaires at the 2 evaluations. The questionnaires also were tested for their internal consistency at the baseline and follow-up evaluations by calculating the Cronbach $\alpha$. The high values obtained for all questionnaires (Table 4 ) at the 2 evaluation times suggest that the items have relatively high internal consistency. All individual MAQLQ subscale scores were significantly correlated with one another; therefore, the overall mean score of the MAQLQ instead of individual MAQLQ subscale scores was used in the modeling analysis. Also, BMQ scores in the concern and necessity domains were significantly correlated $(r=$ $0.40, P<.0001$ ); therefore, the BMQ differential score was used as the predictor in the model. The characteristics of these scores were similar at the 2 evaluations.

The complete case GEE analysis included a total of 286 patients who were nested within 50 physicians. The number of patients within any physician ranged from 1 to 38 . The complete case analysis (286 patients with no missing PROs, $\mathrm{n}=286 \times 2=572$ ) showed that SES, smoking status, and MAQLQ score were statistically significant predictors of asthma control (Table 5). The interaction effect between ACT and ASES scores was not significant. The GEE analysis performed on the 442 patients after using multiple imputation for sensitivity analysis resulted in the same significant predictors, except for age, cardiac-related condition, and ACT score, which were identified as additional statistically significant predictors, and the MAQLQ score was no longer a significant predictor. 
Table 2

Comparing characteristics of subjects with and without complete PROs at t0

\begin{tabular}{|c|c|c|c|}
\hline Variables & $\begin{array}{l}\text { Participants with } \\
\text { complete PROs at } \\
\text { t0 }(\mathrm{n}=286)\end{array}$ & $\begin{array}{l}\text { Participants with } \\
\geq 1 \text { missing PRO } \\
\text { at to }\left(\mathrm{n}=156^{\mathrm{a}}\right)\end{array}$ & $\begin{array}{l}P \\
\text { value }\end{array}$ \\
\hline Age (y), n (\%) & & & .54 \\
\hline $18-39$ & $24(8)$ & $18(11)$ & \\
\hline $40-59$ & $93(32)$ & $47(30)$ & \\
\hline$\geq 60$ & 169 (59) & $91(58)$ & \\
\hline Sex, n (\%) & & & .55 \\
\hline Women & $198(70)$ & $113(72)$ & \\
\hline Men & $88(30)$ & $43(28)$ & \\
\hline SES, n (\%) & & & .79 \\
\hline High & $19(7)$ & $8(5)$ & \\
\hline Low & $70(24)$ & $37(24)$ & \\
\hline Middle & 197 (69) & $111(71)$ & \\
\hline $\begin{array}{l}\text { ED visits (previous year), } \\
\mathrm{n}(\%)\end{array}$ & & & .40 \\
\hline 0 & $183(64)$ & $95(61)$ & \\
\hline 1 & $52(18)$ & $25(16)$ & \\
\hline$\geq 2$ & $51(18)$ & $36(23)$ & \\
\hline $\begin{array}{l}\text { ED visits for respiratory } \\
\text { problems (after1 y), } \\
\mathrm{n}(\%)\end{array}$ & & & .01 \\
\hline 0 & $258(90)$ & $140(90)$ & \\
\hline 1 & $20(7)$ & $4(3)$ & \\
\hline$\geq 2$ & $8(3)$ & $12(7)$ & \\
\hline $\begin{array}{l}\text { Days in hospital } \\
\quad \text { (previous year), n (\%) }\end{array}$ & & & .16 \\
\hline 0 & $232(81)$ & $122(78)$ & \\
\hline 1 & $26(9)$ & $10(6)$ & \\
\hline$\geq 2$ & $28(10)$ & $24(16)$ & \\
\hline \multicolumn{4}{|l|}{ FABA overuse, n (\%) } \\
\hline Previous year & $52(18)$ & $32(20)$ & .64 \\
\hline After $1 \mathrm{y}$ & $54(19)$ & $34(22)$ & .54 \\
\hline \multicolumn{4}{|l|}{ Control status, n (\%) } \\
\hline Previous year & $70(24)$ & $42(27)$ & .65 \\
\hline After $1 \mathrm{y}$ & $75(26)$ & 46 (29) & .53 \\
\hline \multicolumn{4}{|l|}{$\begin{array}{l}\text { Comorbidity indicators, } \\
\mathrm{n}(\%)\end{array}$} \\
\hline $\begin{array}{l}\text { Cardiac-related } \\
\text { conditions }\end{array}$ & $38(13)$ & $27(17)$ & .32 \\
\hline Neurotic disorder & $38(13)$ & $22(14)$ & .92 \\
\hline $\begin{array}{l}\text { Smoking status (previous } \\
\text { year) }\end{array}$ & $43(15)$ & $24(15)$ & 1.00 \\
\hline \multicolumn{4}{|l|}{ PROs, mean \pm SD (range) } \\
\hline ACT & $18.5 \pm 4.5(7-25)$ & $19.1 \pm 4.5(6-25)$ & .23 \\
\hline $\begin{array}{l}\text { BMQ (necessity and } \\
\text { concern scales) }\end{array}$ & $4.7 \pm 5.5(-10$ to 20$)$ & $4.1 \pm 5.9(-10$ to 20$)$ & .29 \\
\hline ASES & $4.2 \pm 0.7(1.1-5.0)$ & $4.0 \pm 0.8(1.2-5.0)$ & .007 \\
\hline AQLQ & $5.4 \pm 1.2(1.1-7.0)$ & $5.4 \pm 1.1(2.3-7)$ & 1.00 \\
\hline
\end{tabular}

Abbreviations: ACT, Asthma Control Test; AQLQ Asthma Quality of Life Questionnaire ASES, Asthma Self-Efficacy Scale; BMQ Beliefs about Medications Questionnaire; ED, emergency department; FABA, fast-acting $\beta$-agonist; PROs, patient-reported outcomes; SES, socioeconomic status; t0, at baseline.

aThree subjects were missing AQLQ scores, 1 was missing an ASES score, 14 were missing ASES, AQLQ and BMQ scores, 29 were missing ACT scores, and 109 were missing all PROs at 1-year follow-up.

The estimated value of the exchangeable working correlation, which models the dependency between the measurements in the same patient at 2 different time points, was 0.45 , and the goodnessof-fit criterion, namely QICu, was 588.5 for the GEE model. Although some predictors, especially the PROs, were not statistically significant for these data, including them in the model resulted in a smaller QICu value, indicating better goodness of fit. The model with PROs (ACT, MAQLQ ASES, BMQ and interaction between ASES and ACT) had a QICu value equal to 598; the model with sociodemographic characteristics (age, sex, and SES) and comorbidities (smoking status, cardiac condition, and neurotic disorder) had a QICu value equal to 621.4; and the model with significant predictors of the reported model had a QIC value equal to 577.2. When the scores of the PROs were added to the model with sociodemographic characteristics and comorbidities, the
Table 3

Comparing outcomes of subjects with and without complete PROs at $\mathrm{t} 1$

\begin{tabular}{|c|c|c|c|}
\hline Variables & $\begin{array}{l}\text { Subjects with } \\
\text { complete } \\
\text { PROs at } \mathrm{t} 1 \\
(\mathrm{n}=286) \\
\mathrm{n}(\%)\end{array}$ & $\begin{array}{l}\text { Subjects with } \\
\geq 1 \text { missing } \\
\text { PRO at } \mathrm{t} 1 \\
\left(\mathrm{n}=156^{\mathrm{a}}\right), \\
\mathrm{n}(\%)\end{array}$ & $P$ value $^{\mathrm{b}}$ \\
\hline ED visits (previous year) & & & .38 \\
\hline 0 & $177(62)$ & $86(55)$ & \\
\hline 1 & $44(15)$ & $29(19)$ & \\
\hline$\geq 2$ & $65(23)$ & $41(26)$ & \\
\hline $\begin{array}{l}\text { ED visits for respiratory } \\
\text { problems (after } 1 \mathrm{y} \text { ) }\end{array}$ & & & $.74^{c}$ \\
\hline 0 & $259(91)$ & $138(88)$ & \\
\hline 1 & $20(7)$ & $14(9)$ & \\
\hline$\geq 2$ & $7(2)$ & $4(3)$ & \\
\hline $\begin{array}{l}\text { Days in hospital } \\
\text { (in previous year) }\end{array}$ & & & .94 \\
\hline 0 & $229(80)$ & $127(81)$ & \\
\hline 1 & $22(8)$ & $11(7)$ & \\
\hline$\geq 2$ & $35(12)$ & $18(12)$ & \\
\hline \multicolumn{4}{|l|}{ FABA overuse } \\
\hline Previous year & $51(18)$ & $32(20)$ & .57 \\
\hline After $1 \mathrm{y}$ & $53(18)$ & $19(12)$ & .11 \\
\hline \multicolumn{4}{|l|}{ Control status } \\
\hline Previous year & $69(24)$ & $42(27)$ & .59 \\
\hline After $1 \mathrm{y}$ & $67(23)$ & $35(22)$ & .91 \\
\hline
\end{tabular}

Abbreviations: ED, emergency department; FABA, fast-acting $\beta$-agonist; PROs, patient-reported outcomes; $\mathrm{t} 1$, at 1-year follow-up.

a Three subjects were missing Asthma Quality of Life Questionnaire scores, 1 was missing Asthma Self-Efficacy Scale scores, 14 were missing Asthma Self-Efficacy Scale, Asthma Quality of Life Questionnaire, and Beliefs about Medications Questionnaire scores, 29 were missing Asthma Control Test scores, and 109 were missing scores for all PROs at 1-year follow-up.

${ }^{\mathrm{b}}$ By $\chi^{2}$ test.

${ }^{c}$ By Fisher exact test (because 1 cell count was $<5$ ).

model had a smaller QICu value compared with the other models. For detecting patients' control status, the cutoff values of the predicted probability $(.1, .2, .3, .4$, and .5$)$ yielded sensitivities of $98 \%$, $83 \%, 49 \%, 34 \%$, and $21 \%$ and specificities of $13 \%, 56 \%, 78 \%, 91 \%$, and $97 \%$, respectively.

\section{Discussion}

In this evaluation of predictors of asthma control for those with complete data, SES, smoking status, and asthma-related quality of life as measured by the MAQLQ were identified as significant predictors of asthma control. This finding has been supported by previous studies. ${ }^{44,45}$ It showed that after adjusting for SES and smoking status, among all the PROs, the MAQLQ was a significant predictor of asthma exacerbations. That is, for every 1-point increase on the MAQLQ score, while keeping the other predictors in the model fixed, there was a 0.25 decrease in the odds of a patient's asthma getting out of control. Using multiple imputations, the sample size was increased by $65 \%$ (442 patients). With the added statistical power, 2 additional variables were found to be significant predictors of asthma control (age and cardiac-related comorbidity) and ACT score was identified as a significant predictor of asthma control instead of the MAQLQ score. This could be due to the correlation between ACT and MAQLQ scores, which was moderate ( 0.63 at baseline and 0.71 at follow-up evaluation). As previously reported by Schatz et $\mathrm{al}^{46}$ in the present study, the correlations of the ACT score with the MAQLQ score were strongest for the symptoms and activity domains $(r=0.63, P<.05 ; r=0.71, P<.01$; $r=0.50, P<0.05 ; r=0.59, P<.01$, respectively), lower with the emotions domain $(r=0.48, P<.05 ; r=0.59, P<.01)$, and lowest with the environment domain $(r=0.38, P<.05 ; r=0.33, P<.01)$.

Furthermore, a review was performed by Schatz ${ }^{47}$ to identify predictors of severe asthma exacerbations. Schatz identified 
Table 4

Descriptive statistics and Cronbach $\alpha$ for patient-reported outcomes at t 0 and $\mathrm{t} 1^{\mathrm{a}}$

\begin{tabular}{|c|c|c|c|c|c|c|}
\hline Variable & $\mathrm{n}$ & Mean & SD & Minimum & Maximum & Cronbach $\alpha$ \\
\hline \multicolumn{7}{|l|}{ ACT } \\
\hline to & 442 & 18.76 & 4.59 & 6 & 25 & 0.78 \\
\hline $\mathrm{t} 1$ & 304 & 18.34 & 4.71 & 4 & 25 & 0.77 \\
\hline \multicolumn{7}{|l|}{ BMQ } \\
\hline t0 & 442 & 4.48 & 5.61 & -10 & 20 & 0.82 \\
\hline $\mathrm{t} 1$ & 319 & 4.99 & 5.45 & -11 & 19 & 0.84 \\
\hline \multicolumn{7}{|l|}{ ASES } \\
\hline t0 & 442 & 4.11 & 0.71 & 1.15 & 5 & 0.89 \\
\hline $\mathrm{t} 1$ & 318 & 2.18 & 0.75 & 1.10 & 5 & 0.88 \\
\hline \multicolumn{7}{|l|}{ MAQLQ } \\
\hline to & 442 & 5.39 & 1.16 & 1.13 & 7 & 0.90 \\
\hline $\mathrm{t} 1$ & 315 & 5.34 & 1.20 & 1.67 & 7 & 0.90 \\
\hline
\end{tabular}

Abbreviations: ACT, Asthma Control Test; AQLQ Asthma Quality of Life Questionnaire; ASES, Asthma Self-Efficacy Scale; BMQ, Beliefs about Medications Questionnaire; t0, at baseline; $\mathrm{t} 1$, at 1-year follow-up.

${ }^{a}$ Mean (SEM) imputed scores at t1: ACT 18.47 (0.26), BMQ 5.05 (0.30), ASES 2.18 (0.04), and AQLQ 5.33 (0.07).

indirectly modifiable risk factors for poor asthma control, such as old age and lower SES, and directly modifiable risk factors, such as allergy triggers, low adherence, comorbidities, absence of specialty care, and various aspects of asthma self-management education. However, Schatz did not mention self-efficacy directly, likely because few studies in asthma have directly included self-efficacy in predictive models. The present study also identified SES, age, comorbidities, and self-efficacy, which is an important aspect of self-management, as important predictors of asthma control.

The positive influence of self-efficacy on patient behaviors has been recognized to play an important role in improving health outcomes for patients with asthma. ${ }^{20}$ Self-efficacy and the level of perceived asthma control, 2 potentially modifiable characteristics, will likely influence self-management and can decrease excess use of reliever medications or urgent care. Enhancing self-efficacy, associated with asthma control early on, can help optimize health behavior in the care management process. The influence of selfefficacy on asthma control can occur much sooner than its influence on health-related quality of life (HRQL). Although self-efficacy has been evaluated as a predictor of HRQL in asthma, ${ }^{48}$ little is known about its influence on controlling asthma exacerbations. To the best of the authors' knowledge, the present study is the first study to explore self-efficacy (ASES) as a predictor of asthma control. The present results indicate that there is little to gain by incorporating measures of self-efficacy or BMQ with the PROs

\section{Table 5}

Generalized estimating equation parameter estimates for the complete case analysis for the 286 patients with all patient-reported outcomes at baseline and follow-up evaluations

\begin{tabular}{lccrc}
\hline Parameter & Estimate & \multicolumn{2}{l}{$95 \%$ Confidence limits } & $\operatorname{Pr}>|\mathrm{Z}|$ \\
\hline Intercept & -0.63 & -1.59 & 0.33 & .2003 \\
Female sex & -0.26 & -0.76 & 0.23 & .2959 \\
Age (18-39 y) & -0.31 & -1.09 & 0.47 & .4332 \\
Age (40-59 y) & 0.37 & -0.10 & 0.85 & .1230 \\
SES (high) & -1.45 & -2.78 & -0.13 & .0316 \\
SES (low) & 0.56 & 0.04 & 1.08 & .0338 \\
Smoker (no) & -0.75 & -1.35 & -0.16 & .0129 \\
Cardiac-related condition (no) & 0.08 & -0.51 & 0.68 & .7771 \\
Neurotic disorder (no) & -0.005 & -0.62 & 0.61 & .9862 \\
ACT & -0.05 & -0.11 & 0.01 & .1203 \\
MAQLQ & -0.25 & -0.47 & -0.04 & .0208 \\
BMQ & 0.02 & -0.02 & 0.05 & .3913 \\
ASES & 0.11 & -0.10 & 0.32 & .3018 \\
ACT $\times$ ASES & -0.004 & -0.05 & 0.05 & .8601 \\
\hline
\end{tabular}

Abbreviations: ACT, Asthma Control Test; ASES, Asthma Self-Efficacy Scale; BMQ Beliefs about Medications Questionnaire; MAQLQ, Mini-Asthma Quality of Life Questionnaire; SES, socioeconomic status.

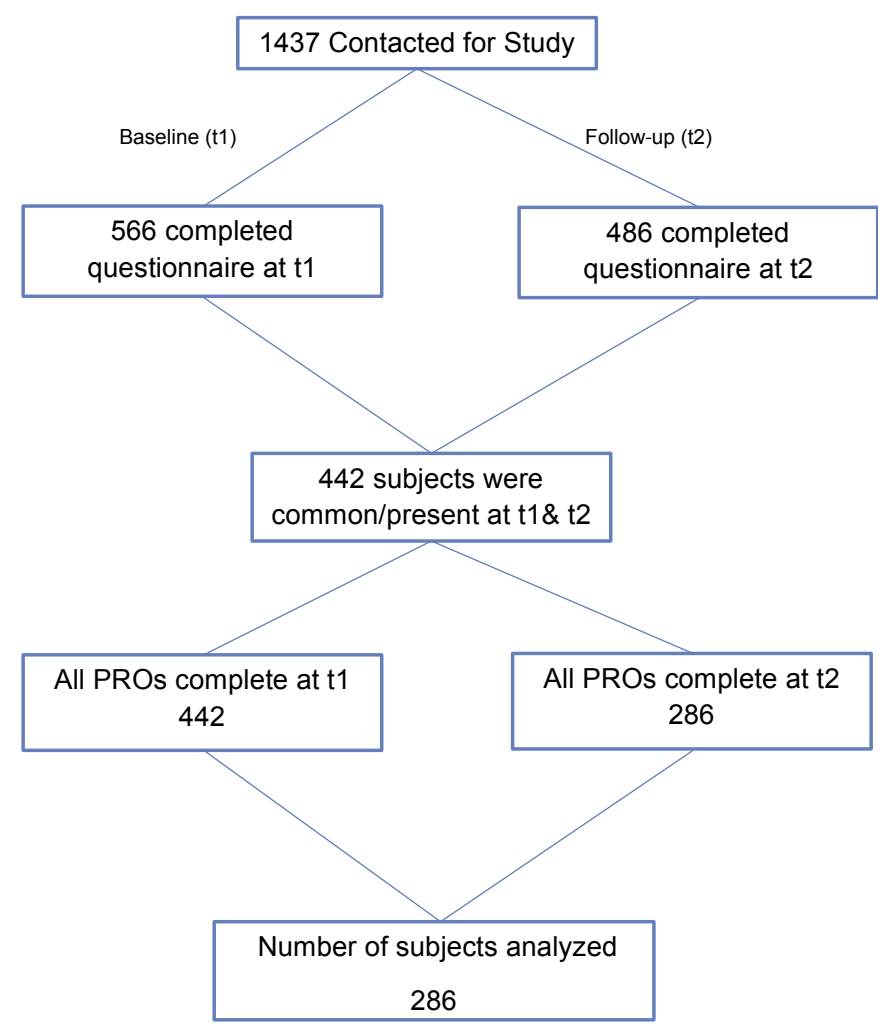

Figure 1. Flowchart describing flow of study participants. PROs, patient-reported outcomes; t1, at baseline; t2, at 1-year follow-up.

obtained from the ACT and MAQLQ in predicting asthma control and the risk of asthma exacerbations. However, the present study population included individuals receiving asthma management in primary care and $70 \%$ were women. Different results might be found in future studies that explore the impact of self-efficacy, HRQL, and beliefs about medication in individuals with more frequent and severe exacerbations, where confidence in managing one's asthma could play a more important role in optimal asthma control.

There was no optimal cutoff point of the predicted probabilities with simultaneous high sensitivity and high specificity for monitoring a patient's risk of exacerbations, but rather a continuum of risk at different values of predicted probabilities. The optimal cutoff point corresponds to a combination of maximum gain in model sensitivity with minimum decrease in its specificity. Therefore, to use this predictive model for classifying patients at high risk of future exacerbation, the cutoff value would have to be decided by primary care physicians based on the acceptable sensitivity and specificity values for a specific scenario. This study is a step toward understanding which characteristics are the strongest drivers of poor asthma control as exemplified by the need for emergency hospital care and excess use of reliever medications.

The present results also support the combined use of PROs, such as self-perceived asthma control as measured by the ACT and HRQL as measured by the MAQLQ, with other clinical and sociodemographic variables obtained from administrative data (for this study, the RAMQ) for predicting future risk of asthma exacerbations. Other studies have supported a similar integrated approach, but none have included a combination of PROs, such as the ACT, MAQLQ, BMQ and ASES, as key predictors. ${ }^{49}$ Including patient reports on behavioral outcomes such as the ACT and MAQLQ are particularly important because these modifiable factors can be used to develop appropriate preventive measures to decrease asthma exacerbations and tailor interventions to individual needs. 
Furthermore, FABA overuse vs ED visits was used to indicate control status based on a previously validated algorithm. ${ }^{10}$ It will be interesting to see if the present conclusions would be different if the 2 outcomes (FABA overuse vs ED visit) were separated. Future work involving secondary analysis of the data will examine this possibility.

\section{Limitations and Future Research}

Many individuals being followed by a primary care physician do not believe they have asthma. Twelve percent of those called refused because they did not remember they had asthma, sometimes believing that asthma is "gone" once the symptoms have resolved. Another limitation of the present sample on which the predictive model is based is the considerably large percentage of women $(70 \%)$ who were smokers; this could be the reason the effect of sex on asthma exacerbations was not statistically significant for the present data. Also, although a patient's MAQLQ score in complete case analysis and ACT score in multiple imputation analysis were statistically significant, the effect size was small. Furthermore, although the MAQLQ score was not significant when missing data were imputed, the model with imputed data identified age and cardiac-related comorbidities as significant predictors, which could suggest that the information contained in the incomplete records was relevant in the prediction of long-term asthma control. Non-completion of questionnaires might be associated with lower self-efficacy and will need to be examined in future work. The authors plan to validate this model further across different populations in future studies to make it clinically relevant.

\section{Conclusions}

The present data highlight the risk factors associated with a patient's risk of poor asthma control. These findings suggest opportunities to decrease the burden on health care by tailoring interventions based on PROs, such as self-perceived asthma control as measured by the ACT and a patient's perception of HRQL as measured by the MAQLQ, which could help in identifying patients at higher risk of having asthma exacerbations. Once clinicians can precisely identify patients with characteristics that place them at higher risk, care teams can intervene to lower the risk of overusing reliever medications and visiting hospital EDs. Further estimation of the predictive value of selfefficacy for identifying future risk of asthma exacerbations is needed to evaluate the usefulness of using this outcome to plan treatment interventions.

\section{Supplementary Data}

Supplementary data related to this article can be found at http:// dx.doi.org/10.1016/j.anai.2015.03.026.

\section{References}

[1] Chapman KR, Ernst P, Grenville A, Dewland P, Zimmerman S. Control of asthma in Canada: failure to achieve guideline targets. Can Respir J. 2001: 8(Suppl A):35A-40A [see comment].

[2] FitzGerald JM, Boulet L-P, McIvor RA, Zimmerman S, Chapman KR. Asthma control in Canada remains suboptimal: The Reality of Asthma Control (TRAC) study. Can Respir J. 2006;13:253.

[3] Reddel HK, Taylor DR, Bateman ED, et al. An official American Thoracic Society/European Respiratory Society statement: asthma control and exacerbations: standardizing endpoints for clinical asthma trials and clinical practice. Am J Respir Crit Care Med. 2009;180:59-99.

[4] Antonicelli L, Bucca C, Neri M, et al. Asthma severity and medical resource utilisation. Eur Respir J. 2004;23:723-729.

[5] Boulet LP, Phillips R, O’Byrne P, Becker A. Evaluation of asthma control by physicians and patients: comparison with current guidelines. Can Respir J. 2002;9:417-423.

[6] Hoskins G, McCowan C, Neville RG, Thomas GE, Smith B, Silverman S. Risk factors and costs associated with an asthma attack. Thorax. 2000;55:19-24.
[7] Kips JC, Pauwels RA. Asthma control: where do we fail? Eur Respir J. 2000;16: 797-798.

[8] Masoli M, Fabian DeniseHolt S, Beasley R. Global burden of asthma: report for the Global Initiative for Asthma. 2004.

[9] Jencks SF, Cuerdon T, Burwen DR, et al. Quality of medical care delivered to Medicare beneficiaries: a profile at state and national levels 4431. JAMA. 2000; 284:1670-1676.

[10] Kawasumi Y, Abrahamowicz M, Ernst P, Tamblyn R. Development and validation of a predictive algorithm to identify adult asthmatics from medical services and pharmacy claims databases. Health Serv Res. 2011;46: 939-963.

[11] Lacasse Y, Archibald H, Ernst P, Boulet LP. Patterns and determinants of compliance with inhaled steroids in adults with asthma. Can Respir J. 2005; 12:211-217.

[12] Laforest L, Yin D, Kocevar VS, et al. Association between asthma control in children and loss of workdays by caregivers. Ann Allergy Asthma Immunol. 2004;93:265-271.

[13] Lowe RA, Localio AR, Schwarz DF, et al. Association between primary care practice characteristics and emergency department use in a Medicaid managed care organization. Med Care. 2005;43:792-800.

[14] Kitch BT, Paltiel AD, Kuntz KM, et al. A single measure of FEV1 is associated with risk of asthma attacks in long-term follow-up. Chest. 2004;126: 1875-1882.

[15] Horne R, Price D, Cleland J, et al. Can asthma control be improved by understanding the patient's perspective? BMC Pulm Med. 2007;7:8.

[16] Bodenheimer T, Lorig K, Holman H, Grumbach K. Patient self-management of chronic disease in primary care. JAMA. 2002;288:2469-2475.

[17] McDonald HP, Garg AX, Haynes R. Interventions to enhance patient adherence to medication prescriptions: scientific review. JAMA. 2002;288: 2868-2879.

[18] Bender BG, Bender SE. Patient-identified barriers to asthma treatment adherence: responses to interviews, focus groups, and questionnaires. Immunol Allergy Clin North Am. 2005;25:107-130.

[19] Emilsson M, Berndtsson I, Lotvall J, et al. The influence of personality traits and beliefs about medicines on adherence to asthma treatment. Prim Care Respir J. 2011;20:141-147.

[20] Clark NM, Dodge JA. Exploring self-efficacy as a predictor of disease management. Health Educ Behav. 1999;26:72-89.

[21] Lorig K, Chastain RL, Ung E, Shoor S, Holman HR. Development and evaluation of a scale to measure perceived self-efficacy in people with arthritis. Arthritis Rheum. 1989;32:37-44.

[22] Lorig K, Feigenbaum P, Regan C, Ung E, Chastain RL, Holman HR A comparison of lay-taught and professional-taught arthritis selfmanagement courses. J Rheumatol. 1986;13:763-767.

[23] Lorig K, Holman H. Arthritis self-management studies-a 12-year review. Health Educ Q. 1993;20:17-28.

[24] Lorig K, Lubeck D, Kraines RG, Seleznick M, Holman HR. Outcomes of self-help education for patients with arthritis. Arthritis Rheum. 1985;28:680-685.

[25] Osborne ML, Vollmer WM, Linton KL, Buist AS. Characteristics of patients with asthma within a large HMO A comparison by age and gender. Am J Respir Crit Care Med. 1998:157:123-128.

[26] Debley JS, Redding GJ, Critchlow CW. Impact of adolescence and gender on asthma hospitalization: A population-based birth cohort study. Pediatr Pulmonol. 2004;38:443-450.

[27] Tamblyn R, Huang A, Perreault R, et al. The Medical Office of the 21st Century (MOXXI): effectiveness of computerized decision-making support in reducing inappropriate prescribing in primary care. CMAJ. 2003;169:549-556.

[28] Chuchalin AG, Svensson K, Stahl E, et al; EPOCH Study Group. A health-related quality-of-life comparison of formoterol (Oxis) Turbuhaler plus budesonide (Pulmicort) Turbuhaler with budesonide Turbuhaler alone and noncorticosteroid treatment in asthma: a randomized clinical study in Russia. Respiration. 2002;69:427-433.

[29] Bandura A. Self-efficacy-toward a unifying theory of behavioral change Psychol Rev. 1977;84:191-215.

[30] Mancuso CA, Rincon M. Impact of health literacy on longitudinal asthma outcomes. J Gen Intern Med. 2006;21:813-817.

[31] Tobin DL, Wigal JK, Winder JA. The Asthma Self-Efficacy Scale. Ann Allergy. 1987;59:273-277.

[32] Nathan RA, Sorkness CA, Kosinski M, et al. Development of the asthma control test: a survey for assessing asthma control. J Allergy Clin Immunol. 2004;113: 59-65.

[33] Schatz M, Sorkness CA, Li JT, et al. Asthma Control Test: reliability, validity, and responsiveness in patients not previously followed by asthma specialists. J Allergy Clin Immunol. 2006;117:549-556.

[34] Juniper EF. Using humanistic health outcomes data in asthma. Pharmacoeconomics. 2001;19:13-19.

[35] Juniper EF, Price DB, Stampone PA, Creemers JP, Mol SJ, Fireman P. Clinically important improvements in asthma-specific quality of life, but no difference in conventional clinical indexes in patients changed from conventional beclomethasone dipropionate to approximately half the dose of extrafine beclomethasone dipropionate 68. Chest. 2002;121: 1824-1832.

[36] Kawasumi Y, Tamblyn R, Platt R, Ernst P, Abrahamowicz M, Taylor L. Evaluation of the use of an integrated drug information system by primary care physicians for vulnerable population. Int J Med Inform. 2008;77: 98-106. 
[37] Lougheed MD, Lemière C, Dell SD, et al. Canadian Thoracic Society Asthma Management Continuum-2010 Consensus Summary for children six years of age and over, and adults. Can Respir J. 2010;17:15.

[38] Schatz M, Zeiger RS, Vollmer WM, et al. Validation of a beta-agonist long-term asthma control scale derived from computerized pharmacy data. J Allergy Clin Immunol. 2006;117:995-1000.

[39] Pan W. Akaike's information criterion in generalized estimating equations Biometrics. 2001;57:120-125.

[40] Pan W. Akaike's information criterion in generalized estimating equations Biometrics. 2004;57:120-125.

[41] Schafer JL. Analysis of Incomplete Multivariate Data. Boca Raton, FL: CRC Press: 2010.

[42] Molenberghs G, Kenward M. Missing Data in Clinical Studies. Volume 61. Hoboken, NJ: John Wiley \& Sons; 2007.

[43] Little RJ, Rubin DB. Statistical Analysis with Missing Data. Volume 539. New York: John Wiley \& Sons; 1987.
[44] Juniper E, Wisniewski M, Cox F, Emmett A, Nielsen K, O’Byrne P. Relationship between quality of life and clinical status in asthma: a factor analysis. Eur Respir J. 2004;23:287-291.

[45] Per Olof E. Quality of Life and Markers of Inflammation: A Study of Asthma in Primary Care. Stockholm: Institutet för miljömedicin, Karolinska Institutet; 2005.

[46] Schatz M, Mosen DM, Kosinski M, et al. The relationship between asthmaspecific quality of life and asthma control. J Asthma. 2007;44:391-395.

[47] Schatz M. Predictors of asthma control: what can we modify? Curr Opin Allergy Clin Immunol. 2012;12:263-268.

[48] Mancuso CA, Rincon M, McCulloch CE, Charlson ME. Self-efficacy, depressive symptoms, and patients' expectations predict outcomes in asthma. Med Care. 2001;39:1326-1338.

[49] Peters D, Chen C, Markson LE, Allen-Ramey FC, Vollmer WM. Using an asthma control questionnaire and administrative data to predict health-care utilization. Chest. 2006;129:918-924. 
eTable 1

Comparison of characteristics of respondents vs nonrespondents

\begin{tabular}{|c|c|c|c|}
\hline Variable & $\begin{array}{l}\text { Respondents } \\
(\mathrm{n}=566), \mathrm{n}(\%)\end{array}$ & $\begin{array}{l}\text { Nonrespondents } \\
(\mathrm{n}=871), \mathrm{n}(\%)\end{array}$ & $\begin{array}{l}P \text { values for test of } \\
\text { difference between groups }\end{array}$ \\
\hline Sex & & & $<.001$ \\
\hline Men & $168(30)$ & 599 (69) & \\
\hline Women & $398(70)$ & $272(31)$ & \\
\hline Age group (y) & & & .42 \\
\hline $18-39$ & 65 (11.5) & $105(12)$ & \\
\hline $40-59$ & $181(32)$ & $250(29)$ & \\
\hline$\geq 60$ & $320(56.5)$ & $516(59)$ & \\
\hline SES & & & .94 \\
\hline Low & $140(25)$ & $222(25)$ & \\
\hline Middle & $387(68)$ & $591(68)$ & \\
\hline High & $39(7)$ & $58(7)$ & \\
\hline ED visits (previous year) & & & .25 \\
\hline 0 & $356(63)$ & $538(62)$ & \\
\hline 1 & $98(17)$ & $132(15)$ & \\
\hline$\geq 2$ & $112(20)$ & $201(23)$ & \\
\hline ED visits for respiratory problems (previous year) & & & .13 \\
\hline 0 & $515(91)$ & $763(88)$ & \\
\hline 1 & $35(6)$ & $71(8)$ & \\
\hline$\geq 2$ & $16(3)$ & $37(4)$ & \\
\hline Number of days in hospital (previous year) & & & .04 \\
\hline 0 & $454(80)$ & $689(79)$ & \\
\hline 1 & $45(8)$ & $48(6)$ & \\
\hline$\geq 2$ & $67(12)$ & $134(15)$ & \\
\hline \multicolumn{4}{|l|}{ Overuse of FABA } \\
\hline Previous year & $102(18)$ & $149(17)$ & .71 \\
\hline After $1 \mathrm{y}$ & 99 (17.5) & $138(16)$ & .45 \\
\hline \multicolumn{4}{|l|}{ Control status (out of control) } \\
\hline Previous year & $142(25)$ & $225(26)$ & .80 \\
\hline After $1 \mathrm{y}$ & $141(25)$ & $209(24)$ & .74 \\
\hline \multicolumn{4}{|l|}{ Comorbidity indicators } \\
\hline Cardiac-related conditions & $83(15)$ & $146(17)$ & .32 \\
\hline Neurotic disorder & $79(14)$ & $140(16)$ & .31 \\
\hline Smoked regularly in previous year & $68(12)$ & $4(1)$ & $<.001$ \\
\hline
\end{tabular}

Abbreviations: ED, emergency department; FABA, fast-acting $\beta$-agonist; SES, socioeconomic status. 